\title{
Comparison of Sensorimotor Training using Chin-Tuck Exercise with Therapeutic Stretching Training on Neck Pain and Mobility in Individuals with Chronic Non-Specific Neck Pain: A pilot randomized controlled trial
}

\author{
Chang-Yong Kim, PT, PhD • Hyeong-Dong Kim, PT, PhD ${ }^{1 \dagger}$ \\ 1Scientific Instruments Reliability Assessment Center, Korea Basic Science Institute \\ ${ }^{1}$ Department of Physical Therapy and School of Health and Environmental Science, College of Health Science, \\ Korea University
}

Received: February 19, 2019 / Revised: February 21, 2019 / Accepted: March 6, 2019

(c) 2019 J Korean Soc Phys Med

\section{| Abstract |}

PURPOSE: Despite the widespread occurrence in the general population, few studies have directly evaluated the effects of shingles on non-specific neck pain (NSNP). This study investigated whether sensory training or therapeutic stretching exercises are more effective in increasing neck mobility and reducing neck pain in chronic NSNP patients.

METHODS: Eighty-one subjects aged between 20 and 32 years with chronic neck pain ( $>$ six months), were allocated randomly to three groups: sensorimotor training group (STG), therapeutic stretching group (TSG), and home exercise group (HEG). All participants received a half-hour training session, three times weekly for six weeks. The outcomes were evaluated using the neck disability index for measuring neck pain, and a universal goniometer to measure the cervical passive range of motion before and after the

$†$ Corresponding Author : Hyeong-Dong Kim

hdkimx1234@daum.net, http://orcid.org/0000-0002-5484-102X

This is an Open Access article distributed under the terms of the Creative Commons Attribution Non-Commercial License (http://creativecommons.org/licenses/by-nc/3.0) which permits unrestricted non-commercial use, distribution, and reproduction in any medium, provided the original work is properly cited. six-week intervention.

RESULTS: The post-test neck disability index scores in the $\mathrm{STG}(\mathrm{t}=4.86)$ and TSG $(\mathrm{t}=3.24)$ were decreased significantly $(\mathrm{p}<.05)$. The passive range of motion changes in all cervical movements in the STG was increased significantly $(\mathrm{p}<.05)$ after intervention compared to those in the other two groups. CONCLUSION: Sensorimotor training using chin tuck exercises may improve neck pain and mobility in subjects with chronic NSNP.

Key Words: Chin tuck exercise, Neck mobility, Non-specific neck pain, Therapeutic stretching training, Sensorimotor training

\section{Introduction}

Pain is an unpleasant sensation associated with actual or potential tissue damage [1]. The sensory processing of affected body parts becomes abnormal and can detect changes in the central information processing system in the state of pain experience and chronic pain $[2,3]$. Moreover, for individuals with neck pain, adjustment of head movement, partial adjustment of the cervical vertebrae, and postural balance are impaired [4]. A cause 
cannot be established conclusively in the majority of patients with neck pain because no identifiable cause of pain can be found. Consequently, most patients are diagnosed with non-specific neck pain (NSNP) [5].

NSNP is a major disabling complaint [6]. College students between the ages of 20 and 30 can easily take their necks by spending a lot of time studying, reading, and working on a computer [6]. These activities are performed by sitting in a static posture with the head bent forward in a chair that is not designed for classrooms, dorms, or apartments [5]. NSNP develops over time. This is because muscle and other soft tissues are tightened because excessive workload is required to maintain head and posture [7]. Muscles of the flexor neck are stretched and weakened. Muscle muscles are shortened in the workload and neural structures remain less than optimal [8].

Sensorimotor dysfunction increases posture fluctuation when measured in an upright position without disturbance $[9,10]$. It has also been demonstrated that the ability to reposition the head in certain predefined locations [11-13] in NSNP patients has been reduced and that eye movement disorders [14] have been compromised. These observations suggest that intrinsic sensory information of the neck muscles is important for ensuring proper control of posture and gaze. Thus, neck coordination exercises have been shown to improve the performance of sensory motor tasks, alleviate neck pain, and reduce posture fluctuations [15-18]. Therefore, the sensory motor function of the cervical vertebrae seems to have a great influence on the general posture.

Postural imbalance of the head to the trunk, such as anterior or posterior head posture, is associated with neck pain complaints [6]. Attempts to correct this mismatch with an ideal posture, such as a neutral posture, are an important component of physical intervention provided to patients with neck pain using a combination of strengthening, stretching, and sensory training [19]. Although improvement in muscle length and strength is expected to improve postural control as a result of exercise, the effects of self-perception on posture should also be considered [20]. Posture correction is under some degree of conscious control. As a result, explicitly exercised programs that include posture assessment and improve posture can enhance participants' posture awareness and potentially alter their habitual posture [19]. Muscle stretching is slow and it is known that muscular connective tissue causes muscle relaxation unless it is torn by microscopy [21]. Muscle stretching is also known to reduce the excitability of motor nerve pools, which can reduce muscle tone, ischemia and pain [22,23]. Interestingly, despite the widespread deployment of posture correction in treatment interventions, there is limited experimental data to support this effect.

Furthermore, few studies have assessed the impact of targeted postural exercises on NSNP directly, despite its widespread occurrence in the general population [8]. Therefore, we investigated whether sensory or therapeutic stretching exercises were more effective in reducing neck pain and neck pain in chronic NSNP patients, and analyzed the effects of sensory exercise training using gingiva exercise based on the above studies.

\section{Methods}

\section{Participants}

Eighty-one (43 women, 38 men) from communities suffering from chronic NSNP volunteered for this study. Before the experiment, the subject was provided with sufficient information on the study and signed the agreement. This study was approved by the Human Ethics Committee's Human Research Sciences and enrolled in the University Clinical Trials Registry. Sample size estimates were based on data collected from previous studies [24-26]. For a $20 \%$ drop-out rate, a priori analysis indicated that more than 22 sample sizes with neck pain in each group were required to obtain statistical power (.90) using a 
general power analysis program (GPower 3.1) [27]. This is based on one-way analysis of variance (ANOVA) measurements for comparison between the three groups, with a predetermined confidence coefficient of .85 [28]. Participants looked at current health and neck symptoms to see if they met inclusion criteria. Subjects who met the following inclusion criteria were recruited: (i) a will to sign a consent form; (ii) at least 5 points in the NDI (29); and (iii) Scale [29]. Participants were excluded if they had certain disorders of the cervical vertebrae such as disk escape, spinal stenosis, postoperative symptoms, severe trauma, convulsive sagittal, peripheral nerve entrapment, fibromyalgia, shoulder disease and inflammatory rheumatic disease.

\section{Outcome Measures}

\section{1) Neck disability index (NDI)}

NDI is a 10-item self-reporting tool for assessing the physical disability of subjects with neck pain [30]. NDI has been shown to be sensitive to high levels of test-retest reliability, validity of internal consistency and tolerance levels, severity levels and changes in severity over time. NDI's failure categories are: 0 to 4 , no failures; 5 to 14 , hardness; 15 to 24 , medium; 25 to 34 years old. If it is 34 or more, it is completed [32]. The results of the retest for the NDI evaluation of 81 participants were highly reliable $(\mathrm{ICC}=.75-.95 ; 95 \% \mathrm{CI}=.64-.97 ; \mathrm{SEM}=$ $.01-1.12 ; \mathrm{p}<.05)$.

\section{2) Measuring cervical passive range of motion (PROM)}

A full circle manual universal goniometer (UG) (Chattanooga, Calif.) Was used to measure the cervical PROM. The measurements were always made with a fixed arm vertical and a movable arm aligned parallel to the virtual line between the ear canal and the endoscope. The recorder records both the beginning and the end of the range of cervical manual motion from the back of the UG goniometer. The recorder records both the starting and ending points of the cervical PROM on the back of the UG shunt scale. The PROM measurements on the cervix were averaged over three experiments. Test-retest testing for cervical PROM measurements was performed on 81 test participants. The results show high reliability (ICC $=.87-.99 ; 95 \% \mathrm{CI}=.80-.99 ; \mathrm{SEM}=.37-8.76 ; \mathrm{p}<.05)$.

\section{Experimental processing}

Fig. 1 outlines the test procedures. Group allocation of the participants was determined using a randomization procedure, in which each participant drew a ball from a basket containing three balls marked with 1 (sensorimotor training group; STG), 2 (therapeutic stretching group; TSG), or 3 (home exercise group; HEG), without looking at the ball. Consequently, the participants and therapists were unaware of their grouping. Table 1 lists the baseline characteristics of all participants in each group. The groups had similar demographic characteristics. One of the most effective postural exercises for combating neck pain is the chin tuck exercise [24], which helps strengthen the muscles that pull the head back into alignment [24]. Therefore, two experimental programs of sensorimotor and stretching training were designed in the chin tuck position. Over a six-week period, the participants in the STG received sensorimotor training and the participants in the TSG performed therapeutic neck stretching training. Training sessions for both the STG and TSG were carried out at the university laboratory. The home exercise for the HEG was performed under periodic supervision (three times a week). All participants received a half-hour training session, three times weekly.

\section{1) Sensorimotor training exercise}

Sensory movement consists of three steps. Within each step, participants worked in different postures, created a support base, and challenged gravity. Each exercise caused automatic and reflex muscle stabilization, allowing part 


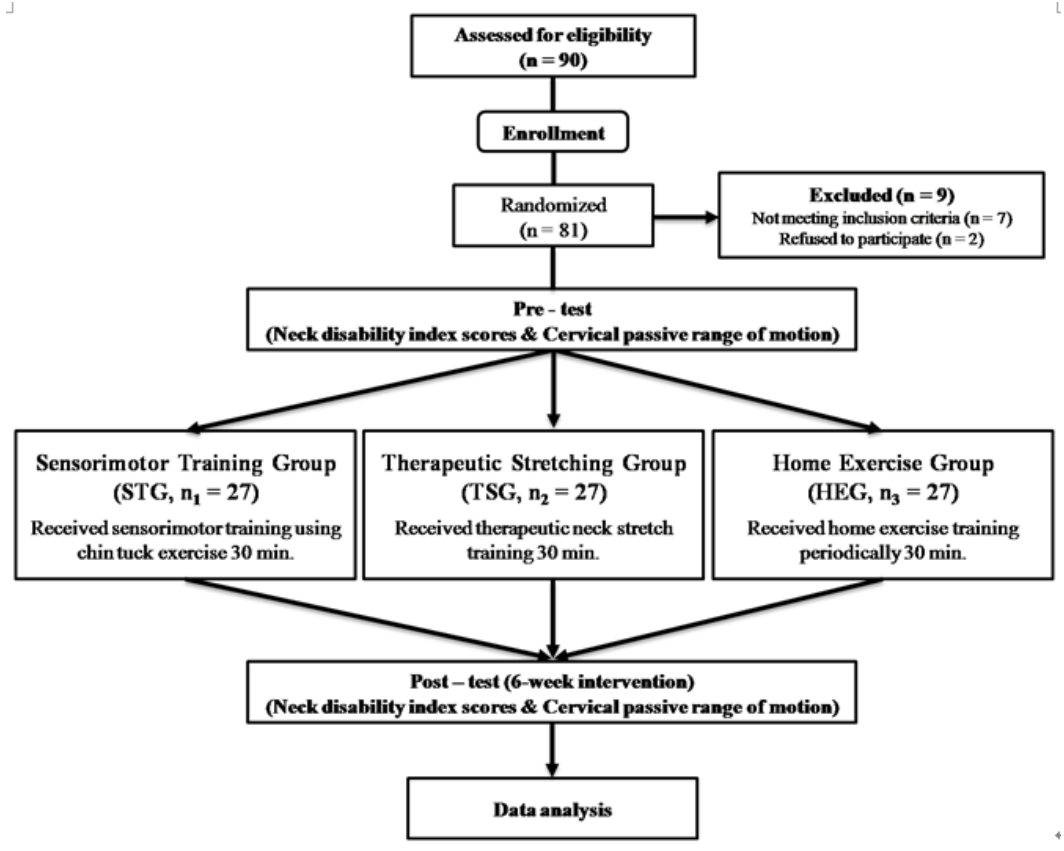

Fig. 1. Experimental Procedures in the Present Study

Table 1. Demographic Characteristics of the Subjects in Each Group

\begin{tabular}{ccccc}
\hline Characteristic & $\begin{array}{c}\text { Sensorimotor training group } \\
\left(\mathrm{STG}, \mathrm{n}_{1}=27\right)\end{array}$ & $\begin{array}{c}\text { Therapeutic stretching group } \\
\left(\mathrm{TSG}, \mathrm{n}_{2}=27\right)\end{array}$ & $\begin{array}{c}\text { Home exercise group } \\
\left(\mathrm{HEG}, \mathrm{n}_{3}=27\right)\end{array}$ & $\begin{array}{c}\chi^{2} / F \\
\left(\mathrm{p}-V^{2}\right)\end{array}$ \\
\hline Age (Years) & $22.981 \pm 3.952$ & $24.911 \pm 2.103$ & $25.772 \pm 3.262$ & $-1.871(.292)$ \\
Weight (kg) & $66.353 \pm 7.101$ & $62.954 \pm 6.291$ & $63.181 \pm 6.990$ & $-1.416(.554)$ \\
Height (cm) & $163.912 \pm 4.293$ & $162.751 \pm 2.912$ & $163.450 \pm 3.821$ & $-2.477(.095)$ \\
Pain duration (Months) & $10.292 \pm 4.192$ & $11.910 \pm 5.011$ & $9.814 \pm 4.341$ & $-1.751(.443)$ \\
Average pain (NRS 0-10) & $5.911 \pm 2.107$ & $5.091 \pm 1.983$ & $4.781 \pm 1.744$ & $-2.183(.121)$ \\
Gender (Male/Female) & $12 / 15^{\mathrm{a}}$ & $14 / 13$ & $12 / 15$ & $.955(.878)$ \\
\hline
\end{tabular}

Values are the mean \pm standard deviation. ${ }^{a}$ Values are numbers. ${ }^{b}$ Inter-group comparison. NRS: Numeric rating scale.

icipants to maintain postural control in a variety of situations. At each stage, participants made unstable surfaces using TOGU equipment such as AeroStep XL, Air Cushion, and Gym Ball (TOGU Co., Germany) [24-26]. (i) Maintain static steps (5 minutes) of posture stability on unstable surfaces focused on sagittal and frontal alignment in AeroStep XL. (ii) Dynamic Stage (10 minutes): Add arm and leg movements while maintaining postural stability in $1 / 4$ posture and standing postures of unstable surfaces. Each task is held for 1 minute and repeated 3 times. (iii) Functional stage (15 minutes): perform functional actions such as occlusion, squatting, and jumping at neutral position of unstable surface.

\section{2) Therapeutic stretching training}

During all exercises, the head was in a neutral position 
Comparison of Sensorimotor Training using Chin-Tuck Exercise with Therapeutic Stretching Training on Neck Pain and Mobility in Individuals with Chronic Non-Specific Neck Pain: A pilot randomized controlled trial I 33

Table 2. Described Procedures According to the Three Stages of Sensorimotor Training Exercises

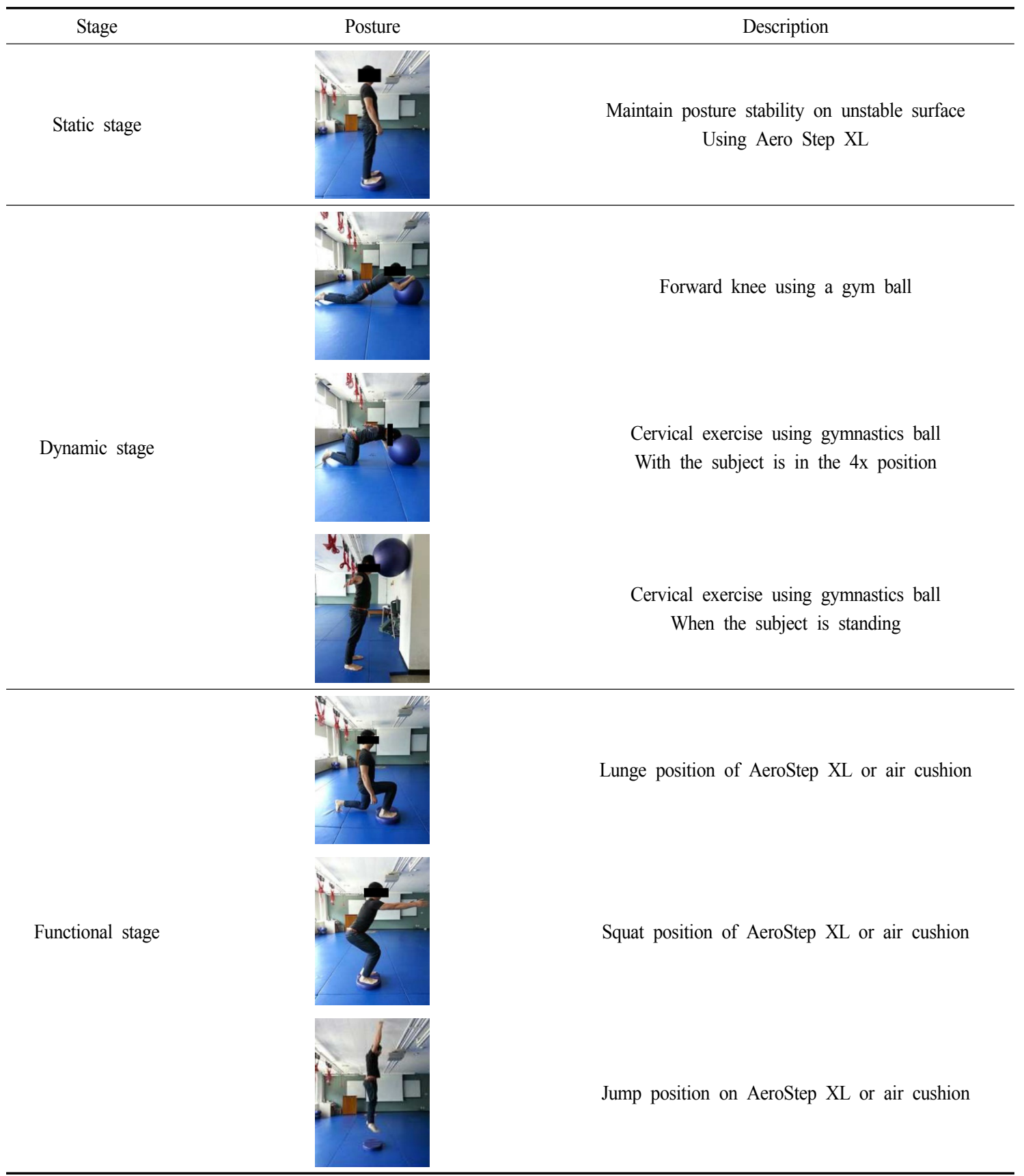

and the neck went straight out of the chin position [25,26]. The treatment stretching training procedure consists of the 12 categories listed in Table 3. TSG participants had to perform each session, set up three sessions, and perform three sessions a day.

\section{3) Home exercise training}

Procedures for home exercise training consist of the five 
Table 3. Described Procedures for the Therapeutic Stretching Exercises

\begin{tabular}{|c|c|}
\hline Muscle & Procedures \\
\hline Upper trapezius muscle & $\begin{array}{l}\text { Gently hold your head while reaching behind your back with your other hand. Tilt your } \\
\text { head until you feel a soft stretch. Wait five seconds. }\end{array}$ \\
\hline Levator scapulae muscle & $\begin{array}{l}\text { Hand on the same scapula. With another hand, stretch your head farther away. Wait five } \\
\text { seconds. }\end{array}$ \\
\hline Chest andbicepsbrachii muscle & $\begin{array}{l}\text { Twist your fingers from behind and squeeze the shoulder blades together. Slowly raise your } \\
\text { arms. Wait five seconds. }\end{array}$ \\
\hline Sternocleidomastoid muscle & $\begin{array}{l}\text { Sit in your chair with your right hand under your right hip and lift your chin. Bring your } \\
\text { left ear to your left shoulder and turn your head to the right. Raise your left hand on your } \\
\text { forehead and stretch for } 5 \text { seconds. }\end{array}$ \\
\hline Scalene muscles & $\begin{array}{l}\text { Hold your back hand so that your arms are straight. Lean your head on one shoulder. Press } \\
\text { and hold for } 5 \text { seconds to switch to another face. }\end{array}$ \\
\hline Neck muscle 1 & $\begin{array}{l}\text { Keeping the rest of your body straight and pushing your chin forward will increase your } \\
\text { throat. Gently tense your neck muscles and wait five seconds. Turn your head to the center } \\
\text { and lift your jaw up and push it back. }\end{array}$ \\
\hline Neck muscle 2 & $\begin{array}{l}\text { Pull your torso down when you pull your arm over your wrist and tilt your head slightly. } \\
\text { Press and hold for } 5 \text { seconds to switch to another face. }\end{array}$ \\
\hline Lying prone in extension & $\begin{array}{l}\text { Depend on the stomach, the floor, and the elbow. Stay in this posture for about } 5 \text { seconds } \\
\text { and make sure your waist is fully extended. }\end{array}$ \\
\hline Press up & $\begin{array}{l}\text { Lie on the stomach, on the floor. Lower your palm down your shoulder. Straighten your } \\
\text { arms and lift the upper trunk up from the floor. Put your pelvis on the floor and let your } \\
\text { back go back to the arch. Wait five seconds. }\end{array}$ \\
\hline Side bends & $\begin{array}{l}\text { Look straight and bend your shoulder toward your head. With your other hand, pull your } \\
\text { right hand down. Press and hold for } 5 \text { seconds to switch to another face. }\end{array}$ \\
\hline Backwards shoulder rolls & $\begin{array}{l}\text { With circular motion, draw both shoulders back, down, forward, and up. The key is to } \\
\text { do this exercise very slowly. Keep acting for } 5 \text { seconds. }\end{array}$ \\
\hline Backwards bending & $\begin{array}{l}\text { Stand your feet up as shoulder width. Keep your knees as straight as possible. Put your } \\
\text { hands firmly at the waist height. Wait five seconds. }\end{array}$ \\
\hline
\end{tabular}

categories described in Table 4. This procedure was completed in accordance with the guidelines reported by Abraham [34]. Participants in the HEG assessed three investigators per week to determine whether exercise was necessary.

\section{Statistical analysis}

Statistical analysis of the data was performed using the SPSS 12.0 software (SPSS Inc., Chicago, IL, USA). The values in each group are expressed as the mean \pm standard deviation and number (n). Parametric methods were used because the samples involved in the present study were represented by normal distribution curves in the Kolmogorov-Smirnov test. A chi-square test (gender) and one-way ANOVA (age, weight, height, pain duration, and average pain) were used to compare the demographic characteristics for the categorical data of the subjects among the three groups. Comparisons of the differences in the NDI scores and cervical PROM changes among the groups' pre- and post-test were investigated using one-way ANOVA for continuous data, followed by a Bonferroni's post-hoc test, to identify the differences among the groups 
Comparison of Sensorimotor Training using Chin-Tuck Exercise with Therapeutic Stretching Training on Neck Pain and Mobility in Individuals with Chronic Non-Specific Neck Pain: A pilot randomized controlled trial I 35

Table 4. Described Procedures for Home Exercise

\begin{tabular}{|c|c|}
\hline Exercise & Procedures \\
\hline Exercise 1: Runner's & $\begin{array}{l}\text { (A) If you can not reach your hands and feet, you can push your right foot forward and } \\
\text { lower it with a sled, place your fingertips on the floor, or place it on two hard cushions. (B) } \\
\text { After inhaling, raise your right leg straight up in one motion. Slowly return to unexpected } \\
\text { position. Repeat four times. Side switching. }\end{array}$ \\
\hline Exercise 2: Standing side & $\begin{array}{l}\text { (A) Hold your feet together and raise your arms straight. Hold your hand with your fingers } \\
\text { crossed and stretch your pointer fingers straight. Inhale while reaching upwards. (B) Bend your } \\
\text { upper body to the right and breathe. Breathe slowly five times. Slowly return to the center. } \\
\text { Repeat on the left. }\end{array}$ \\
\hline Exercise 3: Forward hang & $\begin{array}{l}\text { Bend your knees slightly with your feet wide open. (A) Twist your fingers from behind. Breathe } \\
\text { to broaden your chest and straighten your arms. (B) Exhale at the waist, bend and stretch } \\
\text { your hand toward your head. I wait } 5 \text { breaths deeply. }\end{array}$ \\
\hline Exercise 4: Low lunge arch & $\begin{array}{l}\text { Rush your right foot forward and lower your left knee onto the floor or folded towel / blanket. } \\
\text { (A) Bring your arms in front of your right leg, put your palms on the floor and stick your } \\
\text { thumbs together. (B) Breathe in, stretch your arms over your head, and stretch back comfortably. } \\
5 \text { breaths deep. Side switching. }\end{array}$ \\
\hline Exercise 5: Seated back twist & $\begin{array}{l}\text { Sit on the floor with your legs straight. (A) Bend your right knee and then step on your left } \\
\text { foot. Hold your right hand on the floor and your fingers toward the outside. Bend the left } \\
\text { elbow and turn it to the right and raise the back of your arm against your right knee. Do } \\
\text { not breathe while breathing. (B) Bend your body while twisting your arms against your legs } \\
\text { and looking into your right shoulder. Stop breathing } 5 \text { times slowly and slowly return to the } \\
\text { center. Side switching. }\end{array}$ \\
\hline
\end{tabular}

for each intervention time. A paired t-test was performed to compare the same parameters before and after the intervention within each group. The significance level of the data collected from the subjects set to $\mathrm{p}<.05$.

\section{Results}

\section{Comparison of the NDI scores based on the training methods}

Table 5 summarizes the changes in the NDI scores. Significant pre- to post-test differences were found in the NDI scores of the STG and TSG $(p<.05)$ and the improvement was significantly higher in the STG. Post-hoc testing indicated that in the STG and TSG, the post-test NDI scores $(F=7.593, \mathrm{p}=.012)$ decreased more significantly than those of the HEG.

\section{Comparison of the cervical PROM changes based on training methods}

Table 5 reflects the overall dynamics of the changes in the cervical PROM measurements, and the improvement was significantly higher in the STG. Significant pre- to post-test differences were found in all movements, left lateral flexion, right rotation $(\mathrm{p}<.05)$, flexion, extension, right lateral flexion, and left rotation $(\mathrm{p}<.01)$ in the STG; and extension and left rotation $(\mathrm{p}<.05)$ in the TSG. Post-hoc testing showed that in the STG, the post-test cervical PROM values were significantly higher than those in the TSG and HEG. The post-test cervical PROM values for extension and left rotation $(\mathrm{p}<.05)$ in the TSG were significantly higher than the HEG. 
Table 5. Comparison of Neck Disability Index (NDI) Scores and Cervical Passive Range of Motion (PROM) Changes Among the Three Groups

\begin{tabular}{|c|c|c|c|c|}
\hline Characteristic & $\begin{array}{l}\text { Sensorimotor training group } \\
\left(\mathrm{STG}, \mathrm{n}_{1}=27\right)\end{array}$ & $\begin{array}{l}\text { Therapeutic stretching group } \\
\qquad\left(\mathrm{TSG}, \mathrm{n}_{2}=27\right)\end{array}$ & $\begin{array}{l}\text { Home exercise group } \\
\qquad\left(\mathrm{HEG}, \mathrm{n}_{3}=27\right)\end{array}$ & $F\left(\right.$ p-Value $\left.{ }^{\mathrm{b}}\right)$ \\
\hline \multicolumn{5}{|c|}{ NDI (score) } \\
\hline Pre-test & $16.141 \pm 11.252$ & $12.890 \pm 5.891$ & $11.711 \pm 4.542$ & $-1.031(.091)$ \\
\hline Post-test & $7.570 \pm 7.012^{\dagger}$ & $8.004 \pm 5.161^{\dagger}$ & $11.142 \pm 3.981$ & $7.593(.012)^{*}$ \\
\hline$t(\mathrm{p}$-value $)$ & $4.862(.022 a)^{*}$ & $3.245(.031)^{*}$ & $1.541(.178)$ & \\
\hline \multicolumn{5}{|c|}{ Cervical PROM ( $\left.{ }^{\circ}\right)$} \\
\hline \multicolumn{5}{|c|}{ Flexion } \\
\hline Pre-test & $39.572 \pm 5.261$ & $41.574 \pm 8.906$ & $46.861 \pm 5.642$ & $-1.892(.094)$ \\
\hline Post-test & $48.431 \pm 3.214^{\ddagger \neq}$ & $42.290 \pm 2.109$ & $45.861 \pm 3.972$ & $8.051(.003)^{* *}$ \\
\hline$t$ (p-value) & $-3.373(.012)^{*}$ & $-.934(.748)$ & $.891(.818)$ & \\
\hline \multicolumn{5}{|c|}{ Extension } \\
\hline Pre-test & $47.143 \pm 9.351$ & $51.574 \pm 8.891$ & $69.141 \pm 10.391$ & $-1.965(.061)$ \\
\hline Post-test & $54.861 \pm 11.552^{\dagger \neq}$ & $56.146 \pm 9.110^{\dagger}$ & $68.711 \pm 11.443$ & $5.233(.032)^{*}$ \\
\hline$t$ (p-value) & $-4.787(.003)^{* *}$ & $-3.181(.032)^{*}$ & $.748(.845)$ & \\
\hline \multicolumn{5}{|c|}{ Left lateral flexion } \\
\hline Pre-test & $34.001 \pm 5.772$ & $37.431 \pm 6.246$ & $40.001 \pm 6.144$ & $-.961(.872)$ \\
\hline Post-test & $40.861 \pm 6.992^{\dagger}$ & $39.001 \pm 8.792$ & $38.051 \pm 7.524$ & $5.703(.010)^{*}$ \\
\hline$t$ (p-value) & $-3.253(.012)^{*}$ & $-1.115(.084)$ & $1.303(.074)$ & \\
\hline \multicolumn{5}{|c|}{ Right lateral flexion } \\
\hline Pre-test & $36.432 \pm 4.831$ & $38.296 \pm 7.231$ & $44.861 \pm 5.243$ & $-1.905(.087)$ \\
\hline Post-test & $43.711 \pm 7.041^{\ddagger \ddagger}$ & $38.572 \pm 6.361$ & $42.290 \pm 4.035$ & $6.541(.008)^{* *}$ \\
\hline$t$ (p-value) & $-3.312(.011)^{*}$ & $-.778(.839)$ & $1.935(.069)$ & \\
\hline \multicolumn{5}{|c|}{ Left rotation } \\
\hline Pre-test & $55.861 \pm 8.212$ & $61.431 \pm 11.503$ & $68.572 \pm 9.241$ & $-1.334(.093)$ \\
\hline Post-test & $63.141 \pm 7.677^{\dagger \ddagger}$ & $65.437 \pm 10.295^{\dagger}$ & $66.141 \pm 6.103$ & $5.321(.022)^{*}$ \\
\hline$t$ (p-value) & $-3.251(.013)^{*}$ & $-3.010(.041)^{*}$ & $1.871(.069)$ & \\
\hline \multicolumn{5}{|c|}{ Right rotation } \\
\hline Pre-test & $54.431 \pm 9.221$ & $61.296 \pm 8.483$ & $68.292 \pm 11.284$ & $-1.210(.090)$ \\
\hline Post-test & $63.007 \pm 5.728^{\dagger}$ & $64.296 \pm 11.013$ & $67.861 \pm 10.092$ & $5.982(.010)^{*}$ \\
\hline$t$ (p-value) & $-3.751(.013)^{*}$ & $-1.997(.075)$ & $.456(.954)$ & \\
\hline
\end{tabular}

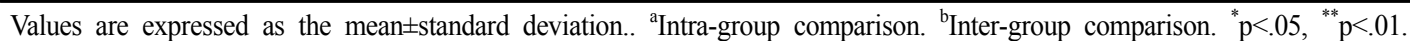

': Significantly different compared to the HEG.

: : Significantly different compared to the TSG.

\section{Discussion}

The present study was designed as a randomized and controlled trial, with a control group undertaking a home exercise program and two experimental groups under constant supervision. This study is unique because the 
improvements were addressed as a result of combining the chin tuck position, a sensorimotor control system, and stretching factors with an exercise program and measurements that captured the aspects of NSNP. Consequently, sensorimotor training had a positive effect on neck pain and cervical PROM throughout all motions. These results suggest that the use of sensorimotor training had positive effects on the maintenance of good posture related to a decrease in neck pain and an increase in cervical PROM.

Neck pain is a common complaint of adults, with a prevalence of $30-50 \%$ per year. This is one of the most common problems encountered in clinical practice [24]. Patients with neck pain exhibit chronic symptoms of recurrence or fluctuation of pain and disability and about one-third of the patients last for more than six months. Therefore, all participants who had chronic neck pain lasting for more than six months were selected in the present study. Moreover, college students aged between 20 and 30 years are particularly susceptible to neck pain because of the many hours spent studying, reading, and working on computers [6]. NSNP develops over time as soft tissues, including muscles, are tightened with the excessive work required to hold the head [7]. Therefore, the participants involved in the present study were college students who performed chin tuck postural exercises to combat neck pain.

The sensory and training stretching exercises used in this study were equally effective in reducing neck pain in the short term. Previous studies have reported no evidence of the long-term effects of passive physical therapy in the treatment of chronic neck pain [35]. The possible reason is that the strength and durability of the neck muscles are not long lasting because manual therapy does not increase resistance to stress. Neck pain can be reduced by treatment, but it can soon recover [36,37]. Passive therapies are not only used to treat chronic neck pain, but they involve neck muscle exercises to obtain long-term results.
Chronic neck pain includes altered motor control of the upper trapezius muscle and greater activation of the accessory neck muscles [38,39]. In addition, the activation of the neck muscles is delayed and lack of automatic feed-forward control of the uterine cervix [39,40] makes the neck vulnerable to accumulated micro trauma and pain. Due to low levels of muscle contraction, pain can alter the excitability of the motor pathways and sensory systems as well as the capillary and intracellular oxygen concentrations [38-40]. Ylinen et al. [35] investigated, after 12 months of stretching, passive neck mobility increased similarly, whereas in the same study neck muscle strengthening group, the improvement was greater than lateral flexion $(22 \%)$. Jordan et al. [41] explained that following passive therapy or intensive training, no significant improvement $(\sim 6 \%)$ was reported in active expansion. After 5 weeks of 3 weeks of therapy, Irnich et al. [36] also reported a better effect than acupuncturebased pain and active neck mobility on existing massages. On the other hand, the improvements disappeared from the 3-month follow-up. Therefore, even if the function of the neck is due to a reduction in neck pain, neck exercises can be improved with neck training.

Sensorimotor training was developed as a part of a treatment approach for chronic musculoskeletal pain syndromes [24,25]. The importance of proprioception in a rehabilitation process has been emphasized. Falla et al. [24] developed specific proprioceptive progression exercises for patients with chronic musculoskeletal pain to restore the normal muscle firing patterns and reflexive stabilization. Sensorimotor training emphasizes progressive challenges for posture control and sensor systems to restore normal exercise programs in patients with chronic musculoskeletal pain. Patients use static rehabilitation tools such as balance boards, foam pads, and elastic bands to perform static, dynamic, and functional phases [24,26]. Based on the above treatment approach, subjects participating in this study conducted various stages of SMT 
with progressive challenges to posture stability through the basis of support, centering, or external issues. The subject should be reminded to maintain proper posture of the three main areas of inherent capacity (neck, waist and feet). So quantity is more important than quality and posture is the most important consideration when performing sensory workouts. The goal of sensory exercise is to increase muscle response and tissue durability rather than joint strength. In the first signs of fatigue, such as an early burning sensation or compensated exercise, exercise is discontinued to avoid additional compensatory movements that can promote disability $[25,26]$. Sensorimotor training improves proprioception, strength, and postural stability in lower extremity rehabilitation [26,42-44]. Sensorimotor training is effective in treating chronic lower back pain, fibromyalgia, and chronic neck pain clinically. These results also show that a greater number of subjects involved in sensorimotor training enhanced their cervical PROM and even decreased their neck pain compared to subjects that were involved in stretching and home exercise training.

The advantageous results of the sensory exercise training using the tuck - in exercises have been proved by the comparison of many groups and groups, but there are some limitations that can be improved in future studies. First, biomechanical measurements such as electromyography were not measured. Therefore, it was not possible to clarify the difference between sensory exercise training and therapeutic stretching. Future research to measure biomechanical parameters and electrograms from cervical muscles such as intestinal perforation and appendicular muscles will provide direct quantitative variables. Second, we could not analyze more parameters that characterize symptom severity or quality of life changes. Thus, the large sample size of the NSNP patient to measure these parameters in various situations provides a direct qualitative information. Finally, this study did not include long-term follow-up observations and it is unclear whether the level of activity that participants can actually perform is actually better. Therefore, these results can not be perceived as a long-term effect of sensory motor training using the subluxation in NSNP patients. Therefore, future RCTs complementing the above restrictions should be performed to confirm the results here.

\section{Conclusion}

This study showed that postoperative pain and mobility were significantly improved compared to other groups, except for extension and left-handedness of the STG. Therefore, sensory movements using the chin-tuck movement of patients with NSNP may have significantly improved neck pain and mobility than treatment stretching or home exercise exercises. In conclusion, sensory motor-based exercise may be a feasible approach to improving neck pain and mobility in NSNP patients due to its clinical advantages and easy application.

\section{References}

[1] Merskey H, Bogduk N. Classification of chronic pain, second edition. IASP Task Force on Taxonomy. Seattle: IASP Press; 1994.

[2] Farina S, Tinazzi M, Le Pera D, et al. Pain-related modulation of the human motor cortex. Neurol Res. 2003;25(2):130-42.

[3] Peyron R, Laurent B, Garcia-Larrea L. Functional imaging of brain responses to pain. A review and meta-analysis. Neurophysiol Clin. 2000;30(5):263-88.

[4] Childs JD, Cleland JA, Elliott JM, et al. American Physical Therapy Association. Neck pain: Clinical practice guidelines linked to the International Classification of Functioning, Disability, and Health from the Orthopedic Section of the American Physical Therapy Association. J Orthop Sports Phys Ther. 2008;38(9):A1-34.

[5] Hogg-Johnson S, van der Velde G, Carroll LJ, et al. The burden and determinants of neck pain in the general 
Comparison of Sensorimotor Training using Chin-Tuck Exercise with Therapeutic Stretching Training on Neck Pain and Mobility in Individuals with Chronic Non-Specific Neck Pain: A pilot randomized controlled trial I 39

population: results of the Bone and Joint Decade 2000-2010

Task Force on Neck Pain and Its Associated Disorders. Spine (Phila Pa 1976). 2008;33(4 Suppl):S39-51.

[6] Miller J, Gross A, D'Sylva J, et al. Manual therapy and exercise for neck pain: A systematic review. Man Ther. 2010;15(4):334-54.

[7] Falla D, Farina D. Neuromuscular adaptation in experimental and clinical neck pain. J Electromyogr Kinesiol. 2008;18(2):255-61.

[8] Martin BI, Deyo RA, Mirza SK, et al. Expenditures and health status among adults with back and neck problems. JAMA. 2008;299(6):656-64.

[9] Field S, Treleaven J, Jull G. Standing balance: a comparison between idiopathic and whiplash-induced neck pain. Man Ther. 2008;13(3):183-91.

[10] Stapley PJ, Beretta MV, Dalla Toffola E, et al. Neck muscle fatigue and postural control in patients with whiplash injury. Clin Neurophysiol. 2006;117(3):610-22.

[11] Armstrong B, McNair P, Taylor D. Head and neck position sense. Sports Med. 2008;38(2):101-17.

[12] Revel M, Andre-Deshays C, Minguet M. Cervicocephalic kinesthetic sensibility in patients with cervical pain. Arch Phys Med Rehabil. 1991;72(5):288-91.

[13] Treleaven J, Jull G, Lowchoy N. Standing balance in persistent whiplash: a comparison between subjects with and without dizziness. J Rehabil Med. 2005;37(4):224-9.

[14] Tjell C, Rosenhall U. Smooth pursuit neck torsion test: a specific test for cervical dizziness. Am J Otol. 1998; 19(1):76-81.

[15] Jull G, Falla D, Treleaven J, et al. A therapeutic exercise approach for cervical disorders. In J. G. Boyling \& G. Jull. Grieve's modern manual herapy: The vertebral column. Edinburgh, Scotland: Churchill Livingstone. 2004;451-70.

[16] Revel M, Minguet M, Gregoy P, et al. Changes in cervicocephalic kinesthesia after a proprioceptive rehabilitation program in patients with neck pain: a randomized controlled study. Arch Phys Med Rehabil.
1994;75(8):895-9.

[17] Röijezon U, Björklund M, Bergenheim M, et al. A novel method for neck coordination exercise--a pilot study on persons with chronic non-specific neck pain. J Neuroeng Rehabil. 2008;23(5):5-36.

[18] Taimela S, Takala EP, Asklöf T, et al. Active treatment of chronic neck pain: a prospective randomized intervention. Spine (Phila Pa 1976). 2000;25(8):1021-7.

[19] Boudreau SA, Farina D, Falla D. The role of motor learning and neuroplasticity in designing rehabilitation approaches for musculoskeletal pain disorders. Man Ther. 2010;15(5):410-4.

[20] Andersen LL, Andersen CH, Zebis MK, et al. Effect of physical training on function of chronically painful muscles: a randomized controlled trial. J Appl Physiol. 2008;105(6):1796-801.

[21] Anderson I. Stretching and sports. In O. Appenzeller \& R. Atkinson. Sports medicine(2nd ed). Baltimore: Urban and Schwarzenberg. 1983;25-120.

[22] Nouwen A, Bush C. The relationship between paraspinal EMG and chronic low back pain. Pain. 1984;20(2):109-23.

[23] Urbscheit NL. Reflexes evoked by group II afferent fibers from muscle spindles. Phys Ther. 1979;59(9):1083-7.

[24] Falla D, Jull G, Hodges P, et al. An endurance-strength training regime is effective in reducing myoelectric manifestations of cervical flexor muscle fatigue in females with chronic neck pain. Clin Neurophysiol. 2006;117(4): 828-37.

[25] Falla D, Jull G, Russell T, et al. Effect of neck exercise on sitting posture in patients with chronic neck pain. Phys Ther. 2007;87(4):408-17.

[26] Häkkinen A, Salo P, Tarvainen U, et al. Effect of manual therapy and stretching on neck muscle strength and mobility in chronic neck pain. J Rehabil Med. 2007;39(7): 575-9.

[27] Faul F, Erdfelder E, Lang AG, et al. G*Power 3: a flexible statistical power analysis program for the social, behavioral, and biomedical sciences. Behav Res Methods. 
2007;39(2):175-91.

[28] Eliasziw M, Young SL, Woodbury MG, et al. Statistical methodology for the concurrent assessment of interrater and intrarater reliability: using goniometric measurements as an example. Phys Ther. 1994;74(8):777-88.

[29] Uthaikhup S, Paungmali A, Pirunsan U. Validation of Thai versions of the neck disability index and neck pain and disability scale in patients with neck pain. Spine (Phila Pa 1976). 2011;36(21):1415e21.

[30] Vernon H, Mior S. The Neck Disability Index: a study of reliability and validity. J Manipulative Physiol Ther. 1991;14(7):409-15.

[31] Stratford PW, Riddle DL, Binkley JM. Using the Neck Disability Index to make decisions concerning individual patients. Physiother Can. 1999;51(4):107-12.

[32] Fairbank JC, Couper J, Davies JB, et al. The Oswestry low back pain disability questionnaire. Physiotherapy. 1980;66(8):271-3.

[33] Youdas JW, Carey JR, Garrett TR. Reliability of measurements of cervical spine range of motion: comparison of three methods. Phys Ther. 1991;71(2):98106.

[34] Abrahams VC. The physiology of neck muscles; their role in head movement and maintenance of posture. Can J Physiol Pharmacol. 1977;55(3):332-8.

[35] Ylinen J, Takala EP, Nykänen M, et al. Active neck muscle training in the treatment of chronic neck pain in women: a randomized controlled trial. JAMA. 2003;289(19):2509-16.

[36] Irnich D, Behrens N, Molzen H, et al. Randomised trial of acupuncture compared with conventional massage and "sham" laser acupuncture for treatment of chronic neck pain. BMJ. 2001;322(7302):1574-8.

[37] Levoska S, Keinänen-Kiukanniemi S, Hämäläinen $\mathrm{O}$, et al. Reliability of a simple method of measuring isometric neck muscle force. Clin Biomech. 1992;7(1):33-7.

[38] Eriksen W. Linking work factors to neck myalgia: The nitric oxide/oxygen ratio hypothesis. Medical Hypotheses. 2004;62(5):721-6.

[39] Ervilha UF, Farina D, Arendt-Nielsen L, et al. Experimental muscle pain changes motor control strategies in dynamic contractions. Exp Brain Res. 2005;164(2): 215-24.

[40] Hodges PW, Moseley GL. Pain and motor control of the lumbopelvic region: effect and possible mechanisms. J Electromyogr Kinesiol. 2003;13(4):361-70.

[41] Jordan A, Bendix T, Nielsen H, et al. Intensive training, physiotherapy, or manipulation for patients with chronic neck pain. A prospective, single-blinded, randomized clinical trial. Spine. 1998;23(3):311-18.

[42] Beard DJ, Dodd CA, Trundle HR, et al. Proprioception enhancement for anterior cruciate ligament deficiency. A prospective randomised trial of two physiotherapy regimes. J Bone Joint Surg Br. 1994;76(4):654-9.

[43] Cleland JA, Childs JD, McRae M, et al. Immediate effects of thoracic manipulation in patients with neck pain: a randomized clinical trial. Man Ther. 2005;10(2):127-35.

[44] Ihara H, Nakayama A. Dynamic joint control training for knee ligament injuries. Am J Sports Med. 1986; 14(4):309-15. 